\title{
Synthesis, Characterization and Bioimaging Applications of Multi-Functional Dendrimer-Based Probes
}

\author{
J. M. Rivera*, J. E. Betancourt, ${ }^{*}$ M.G. Rosario* and E. Rosa-Molinar** \\ *Department of Chemistry, University of Puerto Rico, Río Piedras Campus, San Juan, PR 00931- \\ 3346 \\ **Biological Imaging Group, University of Puerto Rico, Río Piedras Campus, San Juan PR 00931- \\ 1809
}

Live optical imaging is an extremely valuable tool used to streamline biological processes, such as development and regeneration, and therefore determine dynamic parameters such as velocity of motion or/and stability of a structure on one individual at multiple time points [1]. We will show our continued efforts towards the reliable preparation of customized multifunctional probes that allow for the simultaneous visualization using different microscopy modes.

The first generation of multi-functional probes was prepared by the conjugation of mono-sulfoNHS-Nanogold® TDA with $10 \mathrm{KDa}$ molecular weight amino-functionalized dextran conjugated to Texas Red. Such probes have been used as retrograde neuronal tracer in female and male Western Mosquito fish [2]. Even though the preliminary results were promising, the use of a polymeric core (aminodextran) resulted in poor batch-to-batch reproducibility.

Most limitations encountered by using polymeric-based multi-functional probes can be overcome by using dendrimers. Dendrimers are large and complex and usually monodispersed "star shaped" polymers with well-defined chemical structures [3]. They consist of three major architectural components: core, branches, and active sites or end groups and are produced by a sequence of reactions after which each step leads to the formation of a new layer and by consequence a new generation dendrimer. Therefore, one of the most appealing aspects of dendrimer-based technologies is the relative ease by which one can control their size, composition and chemical reactivity [3].

The applications for dendrimers have expanded in many diverse fields such as: drug delivery, diagnostics, catalysis, photo and electro active materials, DNA micro arrays, etc [4]. The structure of dendrimers makes them very good candidates for the precise construction of well-defined multifunctional probes, an aspect of dendrimer-based technology that has no been exploited so far.

Our prototype is based on a poly-lysine peptide being derivatized at the $\varepsilon-\mathrm{NH}_{2}$ in the side chain of a Lys with a functionalized carboxylic acid. The general design of the probes has the following characteristics: modular [5] and iterative solid support synthesis (Figure 1); systematic variation of properties; customizable; biocompatible; quantitative and dynamic.

The synthesis of the dendritic domains (dendronized acids) has been performed as shown in scheme 1. Protection of the terminal hydroxyl groups with $p$-methoxy benzyl moieties (PMB-OH) due to their facile removal and compatibility with Fmoc peptide synthesis. Iterative double substitution reactions on the epichlorohydrin, by $\mathrm{PMB}-\mathrm{ONa}$ or a lower generation dendron, provide the basic subunit (A) that can in turn be further reacted with epichlorohydrin (to make a higher-generation dendron (B)) or alkylated with ethyl bromoacetate followed by hydrolysis, to obtain the desired dendronized acid $(\mathbf{C})$. 
Reference:

[1] Niel, C.M.; Smit, S. J., Annu. Rev. Physiol. 66 (2004) 771.

[2] Rosa-Molinar, E. et al Unpublished results.

[3] Fréchet, J.M., Proc. Natl. Acad. Sci. 99 (2002) 4782.

[4] Zeng, F.; Zimmerman, S.C., Chem. Rev. 97 (1997) 1681.

[5] Grayson, S.M.; Fréchet, J.M. J. Am. Chem. Soc. 122 (2000) 10335.

Figure 1
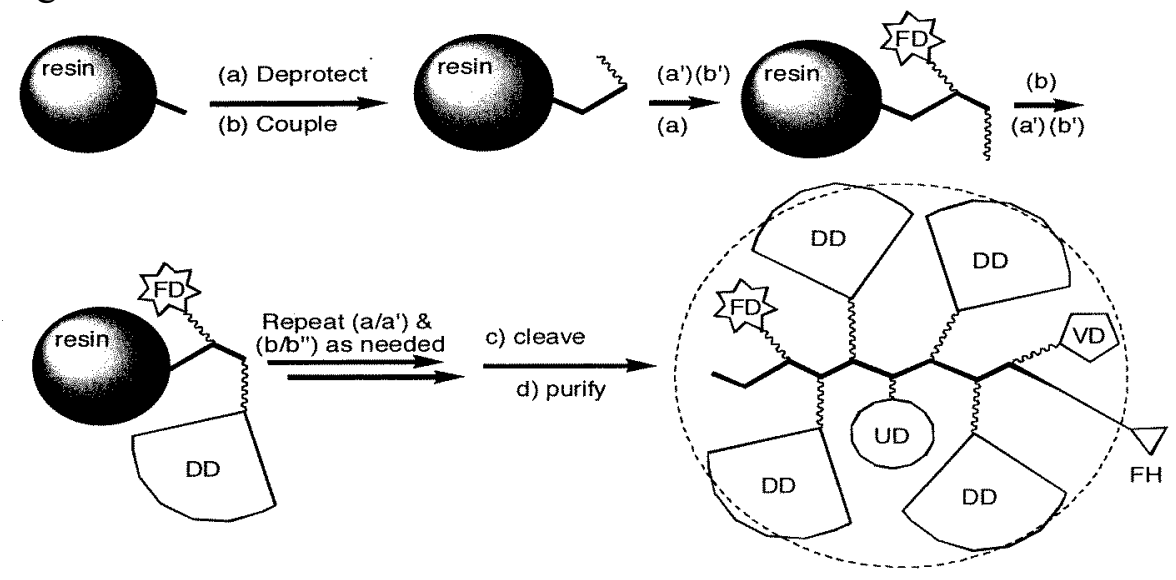

Schematic representation of the multifunctional probes synthesis based on standard Fmoc solid phase synthesis.

Key: Dendritic Domain (DD); Fluorescent Domain (FD); Ultrastructural Domain(UD); Variable Domain(VD); Fixation Handle (FH).

Scheme 1<smiles>C#CCC(O)C(CO)CO</smiles>

A<smiles>[R]OCC(CO)OCC(O)COC(CO)CO</smiles>

B<smiles>[R]CC(CO)OCC(COC(CO)CO)OCC(=O)O</smiles>

$$
\begin{array}{ll}
\mathrm{R}=\mathrm{PMB} & \\
\boldsymbol{i}=\mathrm{PMB}-\mathrm{ONa}, \mathrm{THF}, 65^{\circ} \mathrm{C} & \boldsymbol{i} \boldsymbol{i}=\mathrm{NaH}, \mathbf{1}, \mathrm{THF}, 65^{\circ} \mathrm{C} \\
\boldsymbol{i i i}=\text { Ethyl bromo acetate, } \mathrm{NaH}, \mathrm{THF}, 0^{\circ} \mathrm{C} & \boldsymbol{v i}=\mathrm{NaOH}, \mathrm{THF} / \mathrm{H}_{2} \mathrm{O}
\end{array}
$$

